\title{
Age-gender distribution of coronary artery calcium score in a black African population in Ghana
}

This article was published in the following Dove Press journal: Vascular Health and Risk Management

\author{
George Asafu Adjaye \\ Frimpong ${ }^{1,2}$ \\ Isaac Kofi Owusu ${ }^{3}$ \\ ljeoma Chinedum Anyitey- \\ Kokor $^{4}$ \\ Caitlin Selassie Naa Sarku \\ Wiafe-Kwakye ${ }^{2}$ \\ Evans Aboagye ${ }^{2,5}$ \\ Nana Esi Coleman ${ }^{2}$ \\ Pierre Amankwah ${ }^{4}$ \\ Nakao Kuukua Abaidoo ${ }^{6}$ \\ 'Department of Radiology, Kwame \\ Nkrumah University of Science and \\ Technology, Kumasi, Ghana; ${ }^{2}$ Spectra \\ Health Imaging and Interventional \\ Radiology, Kumasi, Ghana; \\ ${ }^{3}$ Department of Medicine, Kwame \\ Nkrumah University of Science \\ and Technology, Kumasi, Ghana; \\ ${ }^{4}$ Department of Radiology, Komfo \\ Anokye Teaching Hospital, Kumasi, \\ Ghana; ${ }^{5}$ Department of Molecular \\ Medicine, Kwame Nkrumah University \\ of Science and Technology, Kumasi, \\ Ghana; ${ }^{6}$ Department of Surgery, \\ Komfo Anokye Teaching Hospital, \\ Kumasi, Ghana
}

Correspondence: George Asafu Adjaye Frimpong

Department of Radiology, Kwame Nkrumah University of Science and Technology, PMB University Post Office, KNUST, Kumasi, Ghana

Tel +233201169108

Email gafrimpong@gmail.com
Background: Distribution of coronary artery calcium (CAC) has been determined in different heterogeneous populations in the Multi-Ethnic Study of Atherosclerosis (MESA). Based on findings showing that geography and culture can influence CAC scoring beyond traditional race groups, we determined the distribution of CAC in a homogenous black African population to provide an initial basis for a larger CAC score study in Africa.

Methods and results: This is a preliminary study using computed tomography to determine the CAC scores within a black African population who were referred to our center. Other information on patients were recorded through a combination of one-on-one interviews and medical records. A total of 170 patients were involved in our study, including $60.6 \%$ males, with an average age of $53.9 \pm 9.2$ years. The majority $(78.8 \%)$ had a zero calcium score, with patients within the age group of 55-64 years dominating the non-zero calcium score population. Males were found to have higher calcium levels compared to females, and coronary artery calcification and prevalence steadily rose with the increasing age. However, $P$-values of 0.328 and $<0.001$ were observed with distribution of $\mathrm{CAC}$ according to gender and age, respectively.

Conclusion: Findings from this study showed that the distribution of CAC was markedly affected by the age of our study population, which will be more apparent in a larger study.

Keywords: coronary artery calcium, computed tomography, calcium score, coronary artery disease

\section{Introduction}

Coronary artery disease (CAD) is usually linked with arterial wall calcification, and this is evident during computed tomography (CT) at advanced stages of the disease. ${ }^{1}$ In Ghana, coronary heart disease accounts for $6.48 \%$ of total deaths. ${ }^{2}$ The extent of coronary arterial wall calcification is conventionally evaluated by total Agatston score (coronary artery calcium $[\mathrm{CAC}]$ score), which serves as a strong prognostic value for future CAD. ${ }^{3}$ However, thorough risk assessment of patients using CAC score (CS) also depends largely on the average score of an individual with the same gender, age and risk factor profile. ${ }^{4} \mathrm{CS}$ is currently the recommended screening tool for CAD in intermediate-risk asymptomatic patients. ${ }^{5}$ Patients with a CS $>400$ are more likely to develop CAD compared to patients with a CS $<400$, while those with a CS between 1 and 400 have about twice the risk of developing CAD compared to patients with a CS of $0 .^{4}$

Although there have been several studies evaluating the prevalence of high CAC among different ethnic groups such as in the case of the Multi-Ethnic Study of 
Atherosclerosis (MESA), the current research has shown that beyond traditional race groups, factors such as geography and culture can influence calcium scores. ${ }^{6}$ This presupposes that the distribution of CAC might differ for a homogenous black population with a study done in Africa. This study therefore aims to observe the distribution of CAC on the basis of age and gender in a homogenous black community in Ghana employing similar guidelines used in other studies to provide an initial basis for further studies on CAC scoring in the African population.

\section{Methods}

\section{Study population}

The study included patients who were referred to our center (Spectra Health Imaging and Interventional Radiology) for CS using CT between January 2016 and March 2017. These patients were determined to be at intermediate risk for CAD using the Framingham risk score ${ }^{7}$ as a guide and included males who were at the age of 35 years or older, females who were at the age of 40 years or older, those who were black and of African descent and those who had in addition any of these risk factors: family history of heart disease, diabetes, hypertension, dyslipidemia, obesity, sedentary lifestyle and chest pain. Patients who were not black and/or were not of African descent and did not have any of the aforementioned risk factors were excluded.

Information regarding patients' demographics and prevalent risk factors was obtained using a standardized questionnaire, through a combination of one-on-one interview and records of the patients that came along with the referral. The CSs were recorded from a sample of the reports that were issued out to the patients.

Ethical approval for the study was obtained from the Committee on Human Research, Publications and Ethics of Kwame Nkrumah University of Science and Technology and Komfo Anokye Teaching Hospital. Written informed consent was obtained from the participants before their inclusion into the study.

\section{CAC measurement}

The CT scan for the CAC scoring was performed using a 64-slice multi-detector computed tomography scanner (Somatom Definition AS; Siemens, Erlagen, Germany) with the following parameters: tube current 40-60 mAs, tube voltage $100-120 \mathrm{kV}$, collimation $64 \mathrm{~mm} \times 0.6 \mathrm{~mm}$ and rotation time $0.33 \mathrm{~s}$. The examinations were performed with prospective electrocardiographic gating without contrast, and evaluation score was computed using Syngo.via Cardiac following the standard methodology described by Agatston et al. ${ }^{3}$ An acquisition slice difference of $3 \mathrm{~mm}$ was observed, followed by a reconstruction to $0.75 \mathrm{~mm}$ slice thickness. Images were taken mostly on inspiration and were developed from the level of carina to the base of the heart.

\section{Risk factors of cardiovascular disease}

Hypertension was defined as the presence of a persistent elevated SBP $\geq 140 \mathrm{mmHg}$ and/or diastolic DBP $\geq 90 \mathrm{mmHg}$, the use of antihypertensive drugs and/or past medical history of hypertension. ${ }^{8}$ Diabetes mellitus was defined as a random blood glucose level of $\geq 11.1 \mathrm{mmol} / \mathrm{L}$ and/or fasting blood glucose level of $\geq 7.0 \mathrm{mmol} / \mathrm{L}$ or greater and/or use of insulin or an oral hypoglycemic agent. ${ }^{9}$ Dyslipidemia was defined as low levels of high-density lipoprotein cholesterol (men $\leq 1.036 \mathrm{mmol} / \mathrm{L}$, women $\leq 1.295 \mathrm{mmol} / \mathrm{L}$ ), high levels of low-density lipoprotein cholesterol ( $\geq 3.0 \mathrm{mmo} / \mathrm{L})$ and/or hypertriglyceridemia $\geq 1.695 \mathrm{mmol} / \mathrm{L} \cdot{ }^{10,22}$ Obesity/overweight was determined using the body mass index (BMI). The BMI was calculated as the weight of patients in kilograms divided by the square of the height in meters. Obesity and overweight were defined as a BMI $>30 \mathrm{~kg} / \mathrm{m}^{2}$ and a BMI $\geq 25 \mathrm{~kg} / \mathrm{m}^{2}$ but $<30 \mathrm{~kg} / \mathrm{m}^{2}$, respectively, for both women and men. ${ }^{11}$ Family history of heart disease in the sample population was defined as heart disease in a first-degree relative at age $\leq 65$ years and $\leq 55$ years for women and men, respectively. ${ }^{12}$ Following the methodology as described by Martínez-González et al, ${ }^{13}$ sedentary lifestyle was evaluated through the number of hours spent sitting down each week.

\section{Statistical analysis}

Data from the questionnaires were entered into a Microsoft Excel (2010) sheet. Data were cleaned, edited and exported to IBM SPSS version 22 for statistical analysis at a significance level of 0.05 . The CS values were rounded off to the nearest integer, and the resulting data were stratified into three categories $(0,1-400$ and $>400)$ with reference to National Institute for Health and Care Excellence (NICE) guidelines. ${ }^{14}$ Patients who had a non-zero CS were further stratified into low (1-100), moderate (101-400) and severe $(>400){ }^{15}$

\section{Results}

\section{Demographic profile of patients}

A total of 170 subjects at an intermediate risk for CAD underwent CT of the coronary artery from January 2016 to March 2017. The mean age of the patients was $53.9 \pm$ 9.2 years, with the maximum and minimum age being 79 and 36 years, respectively. Majority of the patients were within the age group of $45-54$ years $(n=59,34.7 \%)$, followed very 
closely by patients within the age group of 55-64 years $(\mathrm{n}=$ $58,34.1 \%)$. Patients within the age group of $75-84$ years were minimum, accounting for $2.9 \%(n=5)$. A greater percentage of the patients involved in the study were males $(n=103$, $60.6 \%$ ). The distribution is shown in Table 1 .

\section{Prevalent risk factors for CAD among the study population}

The most prevalent risk factor was hypertension, prevalent in $64.1 \%(n=109)$ of the subjects. Diabetes was the least observed risk factor present in $20 \%(n=34)$ of the patients, as shown in Figure 1.

\section{CAC scores}

The majority had a CS of $0(n=134,78.8 \%)$, followed by those who had scores within the range of $1-400(n=33$, $19.4 \%$ ), with patients who had a CS of $>400$ accounting for the least number $(\mathrm{n}=3,1.8 \%)$ as shown in Figure 2 . The maximum CS was 692.

Further stratification of the patients who had a non-zero CS into low (1-100), moderate (101-400) and severe (>400)

Table I Patients' demographics

\begin{tabular}{ll}
\hline & Frequency, $\mathbf{n}(\%)$ \\
\hline Age (years) & \\
$35-44$ & $31(18.2)$ \\
$45-54$ & $59(34.7)$ \\
$55-64$ & $58(34.1)$ \\
$65-74$ & $17(10.0)$ \\
$75-84$ & $5(2.9)$ \\
Total & $170(100)$ \\
Gender & $103(60.6)$ \\
Male & $67(39.4)$ \\
Female &
\end{tabular}

showed that a total of $36(21.2 \%)$ patients had a non-zero CS, with majority within the low category $(n=30,83.3 \%)$, while moderate and severe categories accounted for three patients each, as shown in Figure 3.

\section{CS and gender}

Majority of the males had a CS of $0(n=79,76.7 \%)$, with a significant number obtaining a CS within the range of $1-400$ $(\mathrm{n}=22,20.4 \%)$. A similar trend was observed in the female population. The three patients who had a $\mathrm{CS}>400$ were all males. The $P$-value for the distribution was 0.328 . A summary of the distribution is shown in Table 2. Figure 4 shows further stratification of patients with non-zero calcium score according to gender. Majority of both males and females under this stratification occupied low category (1-100), accounting for $79.2 \%$ and $91.7 \%$, respectively.

\section{CS and age}

Majority of the patients who had a CS of 0 were within the age group of $45-54$ years $(n=54,40.0 \%)$. The three patients who had a CS $>400$ were in the age group of 55-64 years and 65-74 years. The $P$-value for the distribution was $<0.001$. Table 3 gives a summary of the distribution. Further stratification of the patients with non-zero CS according to age showed that the age group of 55-64 years had the highest percentage of patients with non-zero calcium score $(n=16$, 44.4\%), as shown in Figure 5.

\section{Discussion}

The study presents findings from a black African population in Ghana at intermediate risk for CAD, as determined using Framingham risk score ${ }^{7}$ as a guide, who underwent CT scan to determine their calcium scores. Using a dedicated

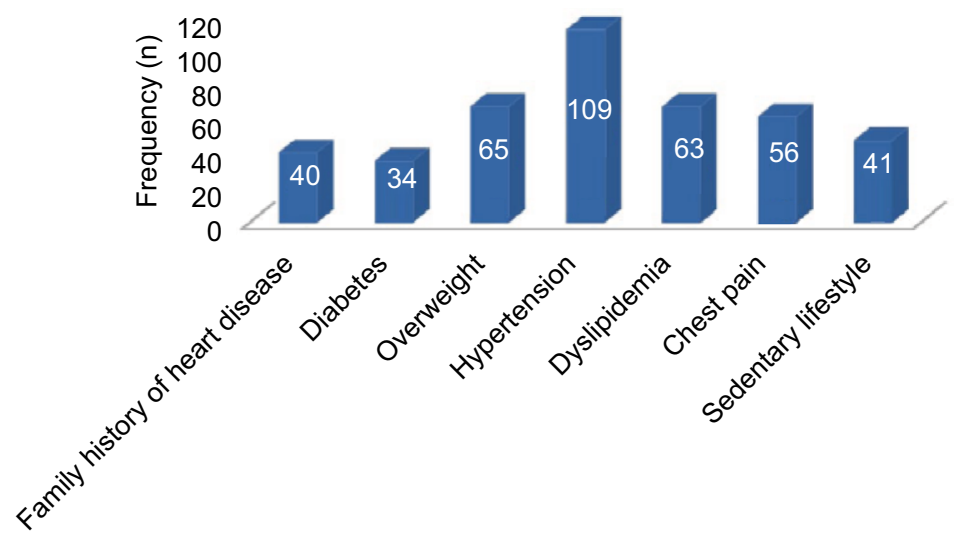

Risk factors

Figure I Number of subjects with risk factors for CAD.

Abbreviation: CAD, coronary artery disease. 


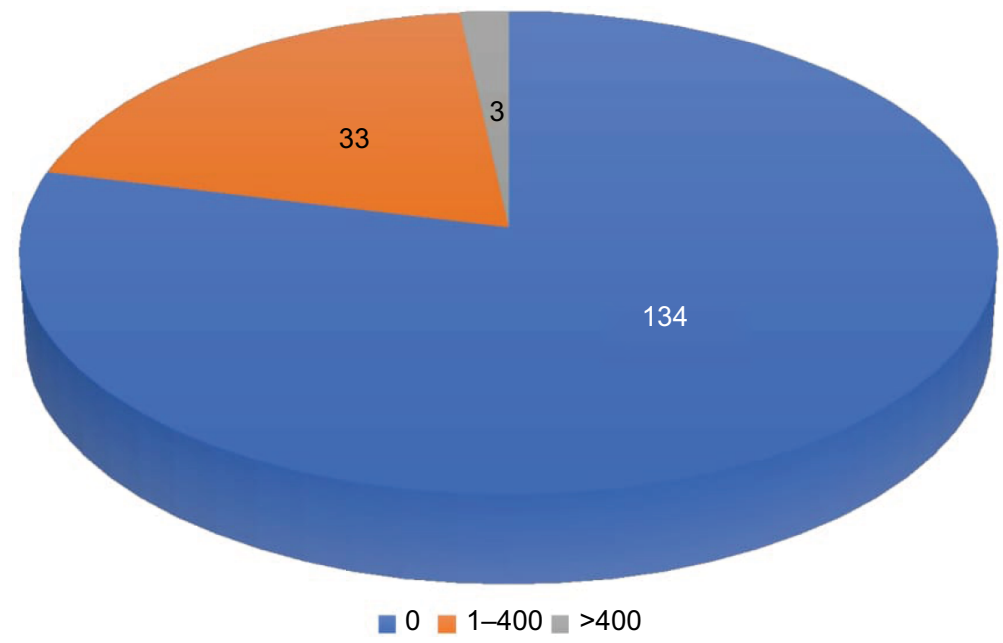

Figure 2 Distribution of calcium score in study population.

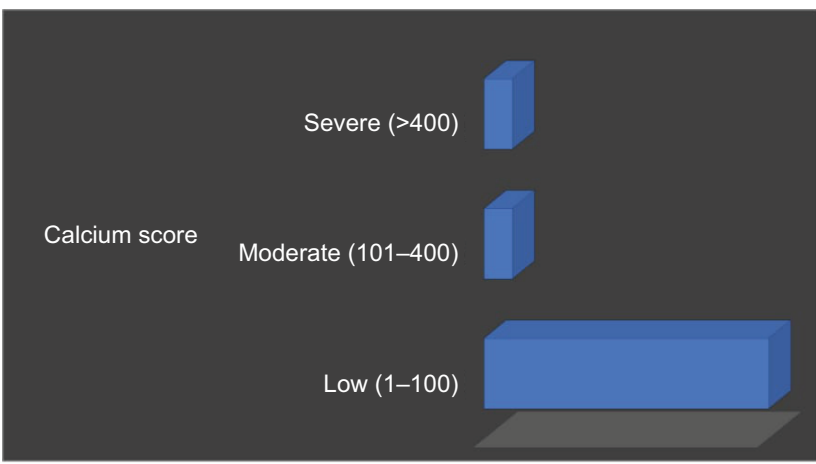

Figure 3 Stratification of patients with non-zero calcium score.

Table 2 Distribution of calcium score and gender of patients

\begin{tabular}{llllll}
\hline Gender & \multicolumn{2}{l}{ Calcium score, $\mathbf{n}(\%)$} & \multicolumn{1}{l}{ Total, } & P-value \\
\cline { 2 - 5 } & $\mathbf{0}$ & $\mathbf{1 - 4 0 0}$ & $\mathbf{7 4 0 0}$ & $\mathbf{n}(\%)$ & \\
\hline Male & $79(76.7)$ & $21(20.4)$ & $3(2.9)$ & $103(100)$ & 0.328 \\
Female & $55(82.1)$ & $12(17.9)$ & $0(0)$ & $67(100)$ & \\
Total & $134(78.8)$ & $33(19.4)$ & $3(1.8)$ & $170(100)$ & \\
\hline
\end{tabular}

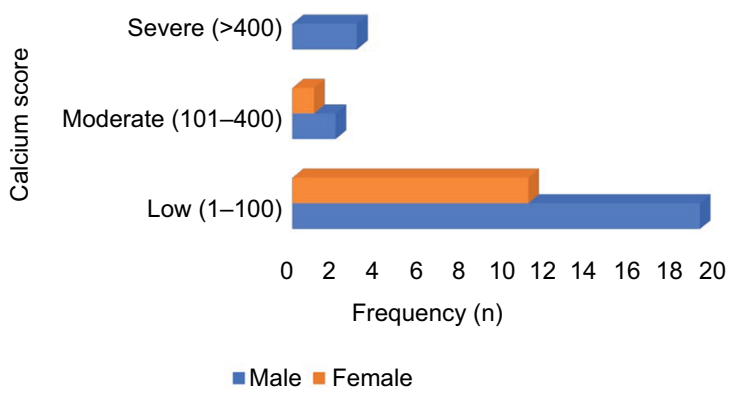

Figure 4 Stratification of patients with non-zero calcium score according to gender.

software, the calcified plaques with color coding for the respective coronary arteries and the Agatston score for each of the respective arteries were depicted (Figure 6). The study
Table 3 Distribution of calcium score and age of patients

\begin{tabular}{llllll}
\hline $\begin{array}{l}\text { Age } \\
\text { (years) }\end{array}$ & \multicolumn{2}{l}{ Calcium score, $\mathbf{n}(\%)$} & Total, & P-value \\
\cline { 2 - 5 } $\mathbf{0}$ & $\mathbf{1 - 4 0 0}$ & $\mathbf{> 4 0 0}$ & $\mathbf{n}(\%)$ & \\
\hline $35-44$ & $28(90.3)$ & $3(9.7)$ & $0(0)$ & $31(100)$ & $<0.00 \mathrm{I}$ \\
$45-54$ & $54(91.5)$ & $5(8.5)$ & $0(0)$ & $59(100)$ & \\
$55-64$ & $42(72.4)$ & $14(24.1)$ & $2(3.4)$ & $58(100)$ & \\
$65-74$ & $9(52.9)$ & $7(41.2)$ & $\mathrm{I}(5.9)$ & $17(100)$ & \\
$75-84$ & $\mathrm{I}(20.0)$ & $4(80.0)$ & $0(0)$ & $5(100)$ & \\
Total & $134(78.8)$ & $33(19.4)$ & $3(1.8)$ & $170(100)$ & \\
\hline
\end{tabular}

is one of the first to determine the age-gender distribution of calcium scores using CT scan in a black African population.

A total of 170 patients were involved in the study. The mean age of the population was $53.9 \pm 9.2$ years, which was slightly higher compared to similar studies done in Brazilians and African Americans. ${ }^{6,16}$ Table 1 shows that majority of the patients were within the age group of $45-54$ years $(n=59$, $34.7 \%$ ), which is in line with that observed by Pereira et $\mathrm{al}^{6}$ in their studies. This further reinforces the observation made by McClelland et $\mathrm{al}^{17}$ that $\mathrm{CAC}$ increases with age. Patients within the age group of 75-84 years were the least represented $(n=5,2.9 \%)$ in the study. This is probably due to the low life expectancy in Ghana, which stands at 61.0 for males and 63.9 for females, ${ }^{18}$ presupposing that majority of patients die before the age of 75 years. Furthermore, majority of the patients were males $(\mathrm{n}=103,60.6 \%)$. Several studies done in calcium score recorded a similar ratio, suggestive of a likely higher prevalence in males compared to females. ${ }^{16,17,19}$

Moreover, the study also included assessment of the traditional risk factors that predisposes patients to CAD. Statistics from the data we collated showed that hypertension was the most prevalent risk factor among the study population $(n=109,64.1 \%)$. Diabetes was the least observed risk 


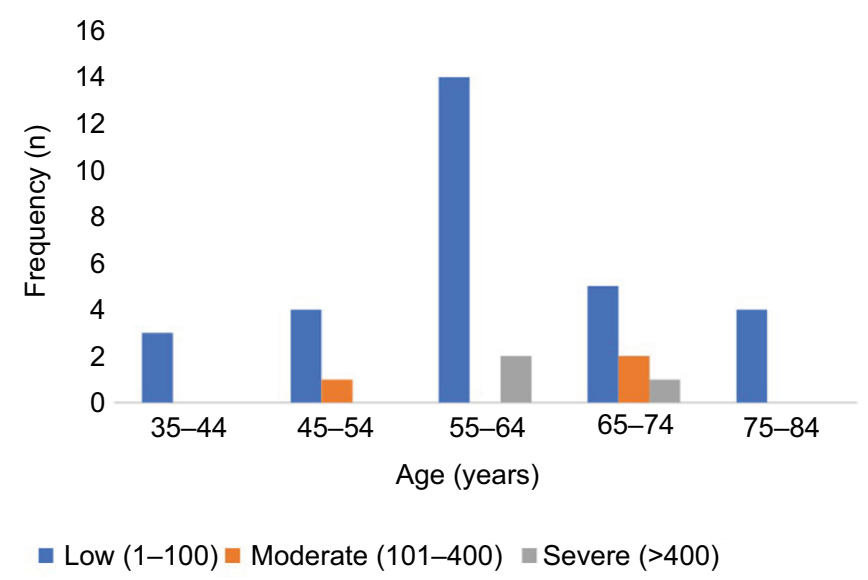

Figure $\mathbf{5}$ Stratification of patients with non-zero calcium score according to age.

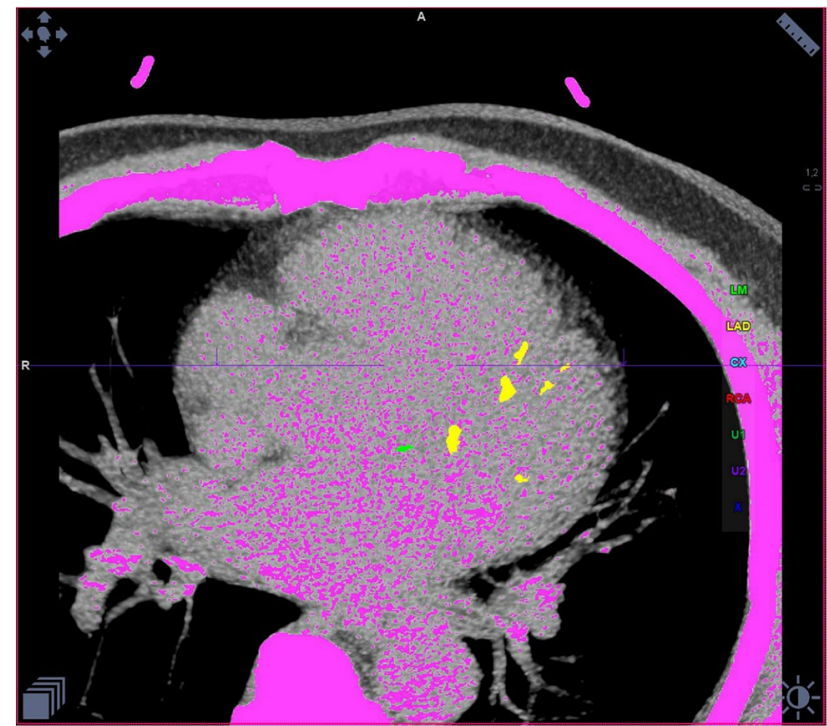

Figure 6 Calcified plaques depicted in color with Syngo.via calcium score software from Siemens (magnification $\times 100$ ).

factor, prevalent in 20\% $(n=34)$ of the patients (Figure 1). A similar trend was observed by Schuhbaeck et $\mathrm{a}^{20}$ in their study on patients with suspected CAD, where hypertension and diabetes accounted for $56 \%$ and $10 \%$, respectively.

As shown in Figure 2, majority of the patients in our study had a CS of $0(n=134,78.8 \%)$, with the CS between 1 and 400 and $>400$ accounting for $19.4 \%(n=33)$ and $1.8 \%(\mathrm{n}=3)$ of patients, respectively. Similar results have been reported by other studies. ${ }^{21,22}$ Further analysis of the CS based on gender showed that the three subjects who had a CS $>400$ were males (Table 2), buttressing the fact that coronary artery calcification is more prevalent in men compared to women. ${ }^{16,17,19}$ However, the $P$-value observed for the distribution as shown in Table 2 indicates that there is not enough evidence to determine the effect of gender on the distribution of CAC. Subsequent analysis based on age revealed that majority of patients in $\mathrm{CS}=0$ category were within the age groups of 45-54 years and 55-64 years. The three patients with $\mathrm{CS}>400$ were found within the age groups of 55-64 years $(\mathrm{n}=2)$ and $65-74$ years $(\mathrm{n}=1)$. In addition, the results showed that four out of the five patients in the age group of 75-84 years had a non-zero CS (Table 3). This suggests further that a rising CS may be associated with an increase in age as noted by other studies. ${ }^{17,21}$ In addition, as observed by Rao et $\mathrm{al}^{21}$ in a similar study that there was a negligible risk of developing $\mathrm{CAD}$ in subjects with $\mathrm{CS}=0$, it presupposes that majority of the patients involved in our study are at a lower risk of developing CAD. The $P$-value observed in Table 3 indicates that the distribution of CAC is significantly affected by the age of our study population.

Figure 3 further shows that a total of $36(21.2 \%)$ patients had a non-zero CS. Further stratification showed that majority were within the low category $(n=30,83.3 \%)$. Subsequent analysis of patients in this category (non-zero CS) based on gender and age is shown in Figures 4 and 5, respectively. The results revealed that patients within the age group of 55-64 years recorded the highest number $(n=16,44.4 \%)$, followed by patients within the age group of 65-74 years ( $n=8,22.2 \%$ ), further reinforcing the opinion that coronary artery calcification steadily increases with increasing age. The observation truly reflected patients at an intermediate risk for $\mathrm{CAD}$, with a lesser percentage $(\mathrm{n}=3,8.3 \%)$ falling within the severe category.

\section{Conclusion}

$\mathrm{CS}$ is the recommended screening tool for individuals at an intermediate risk for CAD. Findings from this study showed that the distribution of CAC was markedly affected by the age 
of our study population, but there was not enough evidence to conclude on the effect of gender, suggesting the need for a larger study comprising a homogeneous black African population. This is necessary for effective management strategies as CS inclusion in the prediction model, which is traditionally based on the risk factors for CAD, markedly influences risk stratification in MESA. ${ }^{23}$

\section{Acknowledgment}

We acknowledge the entire staff of Spectra Health Imaging and Interventional Radiology for their immense support throughout the duration of the study.

\section{Disclosure}

The authors report no conflicts of interest in this work.

\section{References}

1. Becker CR, Knez A, Ohnesorge B, et al. Visualization and quantification of coronary calcifications with electron beam and spiral computed tomography. Eur J Radiol. 2000;10(4):629-635.

2. World Life Expectancy. World Health Rankings. 2017. [updated May 2014]. Available from: http://www.worldlifeexpectancy.com/ghanacoronary-heart-disease. Accessed October 18, 2017.

3. Agatston AS, Janowitz WR, Hildner FJ, Zusmer NR, Viamonte M, Detrano R. Quantification of coronary artery calcium using ultrafast computed tomography. J Am Coll Cardiol. 1990;15(4):827-832.

4. Pletcher MJ, Tice JA, Pignone M, Browner WS. Using the coronary artery calcium score to predict coronary heart disease events: a systematic review and meta-analysis. Arch Intern Med. 2004;164(12):1285-1292.

5. Greenland P, Bonow RO, Brundage BH, et al. ACCF/AHA 2007 clinical expert consensus document on coronary artery calcium scoring by computed tomography in global cardiovascular risk assessment and in evaluation of patients with chest pain: a report of the American College of Cardiology Foundation Clinical Expert Consensus Task Force (ACCF/AHA Writing Committee to Update the 2000 Expert Consensus Document on Electron Beam Computed Tomography) developed in collaboration with the Society of Atherosclerosis Imaging and Prevention and the Society of Cardiovascular Computed Tomography. J Am Coll Cardiol. 2007;49(3):378-402.

6. Pereira AC, Gomez LM, Bittencourt MS, et al. Age, gender, and race-based coronary artery calcium score percentiles in the Brazilian Longitudinal Study of Adult Health (ELSA-Brasil). Clin Cardiol. 2016;39(6):352-359.

7. Lloyd-Jones DM, Wilson PW, Larson MG, et al. Framingham risk score and prediction of lifetime risk for coronary heart disease. Am J Cardiol. 2004;94(1):20-24.
8. Chobanian AV, Bakris GL, Black HR, et al. Seventh report of the joint national committee on prevention, detection, evaluation, and treatment of high blood pressure. Hypertension. 2003;42(6):1206-1252.

9. American Diabetes Association. Diagnosis and classification of diabetes mellitus. Diabetes Care. 2014;37(Suppl 1):S81-S90.

10. Pietroiusti A, Neri A, Somma G, et al. Incidence of metabolic syndrome among night-shift healthcare workers. Int J Occup Environ Med. 2010;67(1):54-57.

11. World Health Organization. Obesity: Preventing and Managing the Global Epidemic (No. 894). Geneva: World Health Organization; 2000.

12. Akosah KO, Schaper A, Cogbill C, Schoenfeld P. Preventing myocardial infarction in the young adult in the first place: how do the National Cholesterol Education Panel III guidelines perform? J Am Coll Cardiol. 2003;41(9):1475-1479.

13. Martínez-González MÁ, Alfredo Martinez J, Hu FB, Gibney MJ, Kearney J. Physical inactivity, sedentary lifestyle and obesity in the European Union. Int J Obes Relat Metab Disord. 1999;23(11):1192-1201.

14. Skinner JS, Smeeth L, Kendall JM, Adams PC, Timmis A, NICE Guidance. Chest pain of recent onset: assessment and diagnosis of recent onset chest pain or discomfort of suspected cardiac origin. Heart. 2010;96(12):974-978.

15. Nakanishi R, Li D, Blaha MJ, et al. All-cause mortality by age and gender based on coronary artery calcium scores. Eur Heart J Cardiovasc Imaging. 2015;17(11):1305-1314.

16. Jain T, Peshock R, McGuire DK, et al. African Americans and Caucasians have a similar prevalence of coronary calcium in the Dallas Heart Study. J Am Coll Cardiol. 2004;44(5):1011-1017.

17. McClelland RL, Chung H, Detrano R, Post W, Kronmal RA. Distribution of coronary artery calcium by race, gender, and age. Circulation. 2006;13(1):30-37.

18. World Life Expectancy. World Health Rankings. 2015. Available from: http://www.worldlifeexpectancy.com/ghana-life-expectancy. Accessed October 18, 2017.

19. Hulten E, Bittencourt MS, Ghoshhajra B, et al. Incremental prognostic value of coronary artery calcium score versus $\mathrm{CT}$ angiography among symptomatic patients without known coronary artery disease. Atherosclerosis. 2014;233(1):190-195.

20. Schuhbaeck A, Schmid J, Zimmer T, et al. Influence of the coronary calcium score on the ability to rule out coronary artery stenoses by coronary $\mathrm{CT}$ angiography in patients with suspected coronary artery disease. J Cardiovasc Comput Tomogr. 2016;10(5):343-350.

21. Rao A, Yadu N, PimpalwarY, Sinha S. Utility of coronary artery calcium scores in predicting coronary atherosclerosis amongst patients with moderate risk of coronary artery disease. JICC. 2017;7(2):55-59.

22. Diederichsen SZ, Grønhøj MH, Mickley H, et al. CT-detected growth of coronary artery calcification in asymptomatic middle-aged subjects and association with 15 biomarkers. JACC Cardiovasc Imaging. 2017;10(8):858-866.

23. Polonsky TS, McClelland RL, Jorgensen NW, et al. Coronary artery calcium score and risk classification for coronary heart disease prediction. JAMA. 2010;303(16):1610-1616.
Vascular Health and Risk Management

\section{Publish your work in this journal}

Vascular Health and Risk Management is an international, peerreviewed journal of therapeutics and risk management, focusing on concise rapid reporting of clinical studies on the processes involved in the maintenance of vascular health; the monitoring, prevention and treatment of vascular disease and its sequelae; and the involvement of

\section{Dovepress}

metabolic disorders, particularly diabetes. This journal is indexed on PubMed Central and MedLine. The manuscript management system is completely online and includes a very quick and fair peer-review system, which is all easy to use. Visit http://www.dovepress.com/ testimonials.php to read real quotes from published authors. 